\title{
First Language Acquisition: Psychological Considerations and Epistemology
}

\author{
Davood Mashhadi Heidar \\ Department of English, Khorasgan (Isfahan) Branch, Islamic Azad University, Isfahan, Iran \\ Email: davoodm_tarbiatmodares@yahoo.com
}

\begin{abstract}
This article aims to provide an overview of major theoretical approaches and psychological considerations related to child language (first language acquisition). The field is multidimensional, as illustrated by the many courses on child language or language acquisition that are taught in departments of Linguistics, Psychology, Cognitive Science, Speech Pathology, Education, and Anthropology. This crossdisciplinary nature of the field is also reflected in many handbooks and articles yearly published across the world. In this article I mainly present a general overview of theoretical/epistemological and classical/modern accounts and approaches to the study of first language acquisition. In other words, the present paper is to investigate the psychological/epistemological considerations of first language acquisition with the aim of shedding a bit of light on this human-species phenomenon.
\end{abstract}

Index Terms - first language acquisition, cognitive science, speech pathology, education

\section{INTRODUCTION}

Scientific interest in this area has, as one would look ahead to, shown itself in both theoretical and practical dimension. However, briefly, arguments relating to first language acquisition have been tied in to arguments about particular models of language acquisition and hence about particular conceptions of language. Probably the most renowned example of the theoretical dimension is the linkage of the notion of such arguments to the 'innateness hypothesis', the idea that language acquisition is only possible because of an inborn 'language faculty'. Of course, the connection between the age factor and this hypothesis is quite straightforward. If there is an innate language faculty and language develops in a way similar to, say, a physical organ or bipedal locomotion (Chomsky, 1988), one can expect to be able to identify age-related stages in such development and periods of particular readiness for such development. To the extent that such age-related phases are discoverable, they can be represented as supportive of the innateness hypothesis. The matter does not just rest there. The innateness hypothesis has even more ramifications. If there is a faculty concerned specially with language which is inborn, this not only sets language apart from behaviors which are acquired purely from the nurturing environment, but also suggests that language is an indispensable, perhaps defining, part of the human make-up, and renders very reasonable the notion that language is peculiar to our species.

The age effects on the acquisition of first language have been explored by many linguists and applied linguists since the 1960's (e.g. Lenneberg, 1967; Schachter, 1988; Long, 1990) and the existence of critical period for language acquisition has been one of the controversial issues in first language acquisition research. The results of SLA research are also both interesting and confusing. Some make an analogy between the first and second language acquisition and hypothesize that there is also an age of onset (AO) for second language learners. To put it in another way, some applied linguists (e.g. Cook, 1995) believe that undoubtedly children are probably believed to be better at learning second languages than adults. People always know one friend of acquaintance who started English as an adult and never managed to learn it properly and another who learned it as a child and is not distinguishable from a native; whereas, the results of some other studies indicate that adult language learners can attain native like proficiency in a second or a foreign language. That is, there are still some late beginners who in spite of their old age were able to learn a second language exactly like early beginners and some cases have been reported who acquired near native like performance in different subparts of a language such as pronunciation and grammaticality judgments.

As different theoretical dimensions are at work in explaining the astonishing phenomenon of first language acquisition, this paper is an attempt to shed light on the issue under discussion. To put it in another way, the present paper is to investigate the psychological considerations of first language acquisition with the aim of shedding a bit of light on this human-species phenomenon.

\section{CRITICAL PERIOD REVISITED}

The commonly held view that there is a 'critical period' for the acquisition of language is not normally subjected to more than rather superficial inspection. The majority of adults merely take it for granted that children are of their nature endowed with the ability to acquire their mother tongue with almost no effort. Psychologists often regard the matter in a similarly self-evident fashion but endow the assumptions they make with scientific documentations by introducing 
concepts and terminology from such areas as neuropsychology and nativist linguistics. Quite obviously the Critical Period Hypothesis, like other hypotheses, enjoys its own critics. Indeed, the question of whether there is a critical period for language acquisition has bred strong debates among scholars and the debates seem to rest there forever. The discussion seems to be of the same interest to both L1 and L2 acquisition researchers. For some scholars the Critical Period Hypothesis is important because the notion of maturational constraints on language acquisition is considered to be related to the idea that language acquisition is possible via special bioprogramming. With respect to language education, the Critical Period Hypothesis has corollaries regarding decision-making about the starting point for the instruction of L2 at schools. However, in this article L1-related issues are of priority and L2-related evidence is left for SLA researchers.

\section{On the nature of critical Period}

Biologically point of view, Critical period, is the term used in biology to refer to a limited phase in the development of an organism during which a particular activity or competency must be acquired if the activity or the competency is to be incorporated into the behavior of that organism. The critical period for a behavior is within these time limits. The term critical period has been used by linguists and applied linguists to explain language acquisition. If language acquisition in human beings is strictly constrained by the boundaries of a critical period, the implication is that L1 acquisition begins only at the inception of this period and does not happen at any other time. An extra implication may be that even if L1 acquisition begins within the critical period it does not carry on away from the end of that period. Lenneberg (1967), who is normally recognized as the 'father' of the Critical Period Hypothesis, refers to the critical period as beginning at the age of two and ending about puberty. This period overlaps with the lateralization process; that is, the specialization of each hemisphere of the brain to take over different functions. Lenneberg mentions a variety of evidence of changes in the brain happening all through the period under debate. However, his assertion that lateralization ends at puberty has been significantly challenged by later studies reinterpreting the relevant data as indicating that the process is already complete in early childhood (see e.g. Kinsbourne \& Hiscock, 1977; Krashen, 1973). One can make a distinction between a weaker and a stronger version of the Critical Period Hypothesis. The weaker version argues that language acquisition has to begin within the critical period, and that if language acquisition begins immediately after the inception of the critical period it will be more effective. The stronger version presumes that even if language acquisition begins within the critical period it does not go on past the end of the period.

\section{The truthfulness of the critical period hypothesis}

This part of the paper dealt with an introduction to and definition of Critical Period Hypothesis with regard to First Language Acquisition. Lenneberg (1967) claimed that the inception of the critical period is at two years of age and that puberty constituted the stop point for the critical period. Although the contribution of Lenneberg (1967) to this theoretical framework was praiseworthy, his claim, in the light of evidence from neurological research, from deaf studies, and from other studies, was discussed and shown to be improbable and that language acquisition is in process from birth forwards and a well-defined cut-off point where L1 acquisition ceases cannot be pointed to unambiguously. While there is some evidence to support the existence of some linguistic advantages in line with early L1 acquisition, there are no clear foundations for accepting that language acquisition definitely cannot crop up after puberty. Moreover, post-pubertal L1 acquisition in the normally developing population was looked at and the conclusion was made that L1 acquisition continues into early adulthood and indeed, at least in the realm of semantics and pragmatics, it carries on to middle age and even onwards. All things considered, the available evidence does not clearly support the notion of a critical period for L1 acquisition.

\section{Classical APPROACHeS to EPISTEMOlOGY: NATIVIST AND EMPIRICIST APPROACHES}

If you look at psychology books from the 1940s and 1950s, you will find that what we now call "language acquisition" tended to be described as the "acquisition of verbal habits." This reflects the ideas of behaviorist psychologists like B.F.Skinner and his predecessors who viewed children's language learning as a rather passive process of imitating the speech they heard from adults, accompanied by positive reinforcement when they got it "right" and negative reinforcement when they got it "wrong." In other words, there was no essential difference between the way a rat learns to negotiate a maze and a child learns to speak. The problem with the notion of reinforcement as a mechanism for language acquisition is that it is difficult to see quite how it would work with young children, considering the complexity of the linguistic system they must acquire. Parents put a great deal of effort into keeping conversations with their young children going, but only very rarely do they explicitly approve or disapprove of their children's grammar. When they do comment in some way about mistakes, we often see that the children either "miss the point" or resolutely stick to their version. Here are just two examples:

Child: Nobody don't like me.

Parent: No, say "nobody likes me."

Child: Nobody don't like me.

(the above sequence is repeated eight times)

Parent: No, now listen carefully; say "nobody likes me."

Child: Oh! Nobody don't likes me.

Child: Want other one spoon, daddy. 
Parent: You mean, you want the other spoon.

Child: Yes, I want other one spoon, please Daddy.

Parent: Can you say "the other spoon"?

Child: Other...one...spoon.

Parent: Say "other."

Child: Other.

Parent: "Spoon."

Child: Spoon.

Parent: "Other spoon.” (Data from Braine, 1971)

Child: Other...spoon. Now give me other one spoon?

There are even bigger problems with imitation. Children do sometimes imitate what they hear, but they clearly do much more than that. They also construct rules to produce forms of the language that they could not have heard from adults, for example, words such as mouses and hitted, and sentence structures such as Don't say me that!

A rationalist perspective proposes some innate competence (thus the term "nativist" is often used). In a classical empiricist paradigm, "learning" based on input explains all knowledge; the Initial State therefore is a tabula rasa. (See Wilson 1999 for overview) These approaches differ in the form of reasoning which they recognize to underlie knowledge acquisition. Induction (building on direct experience of input data) is central to an empiricist paradigm; deduction (which does not depend on experience of data to confirm conclusions) to a rationalist paradigm. All in all the two classically opposed approaches to the representation and acquisition of knowledge differ in their views of: (a) the ultimate source of knowledge (external and led by environmental input or internal, led by the structure of the mind); (b) mechanisms of acquisition; (c) characteristics of the Initial State, i.e., whether or not innate "knowledge" of some form exists.

\section{Hermeneutic theories of child language acquisition}

\section{Nature versus nurture}

The ancient theories of child language acquisition explore the dilemma of nature versus nurture; that is, whether language is inherent and God-given or learned from environment.

\section{Behaviorism: Environmentalist theories}

Behaviorist studies both in psychology and linguistics originate in the beginning of the 20 th century. They claim that child language acquisition is governed by habit forming and reinforcement by imitation, repetition, and analogy. The newborn's mind as a blank slate 'tabula rasa' is borrowed from the era of Illumination. It was a still progressive phenomenon in comparison with solely religious explanation of child language acquisition on one hand, and on the other, with persons' classification through their social origin, otherwise, with a genealogical identification and evaluation of one's mental capacities by their birth in a social class.

The most eminent representative of behaviorism, B.F.Skinner came up with the concept of operant conditioning. Language acquisition is a learned set of habits. Structural linguistics claims that languages differ from each other without limits. A linguist observes and describes only the speech, performance, parole, i.e., the 'publicly observable responses' analyzing language units till they become inseparable (sentence diagramming, words, affixes, endings, phonemes, and phoneme distinguishing features). According to classical behaviorism stimuli and responses create human behavior on 'tabula rasa.' A psychologist should rigorously describe only what is objectively perceived, recorded, measured. Concepts of consciousness, innateness, intuition, thinking processes were outside the domain of observable, hence any research.

\section{Innatism or nativism}

The nativistic approach to child language acquisition originated as a direct antipode to behaviorism in the late 50ies of the 20 th century and dominated the field until the last decade. Nativists claim that children are born with an innate ability to acquire language because they do have language innately. The Universal Grammar [UG] is hard-wired in brain, which contains a language acquisition device [LAD]. UG is the grammar of the human language, that is, the universal principles of organizing all languages. This is the reason children can accomplish cognitively a very challenging task of language acquisition even though they are still unable to do some simpler, cognitively less demanding things.

\section{A rationalist approach}

Noam Chomsky (1959) in his criticism of the behaviorist approach to language acquisition, in contrast to Skinner, proposed (and continues to propose) that children actively construct the rule systems of their native language aided by a brain already pre-wired with a special language capacity that is separate from other types of mental abilities. While current approaches to language acquisition all concentrate much more on the child actively building their knowledge of language, they still tend to divide along nativist and empiricist lines. A nativist approach, like Chomsky's Principles and Parameters Theory proposes a fair amount of inborn knowledge in the child. That is, knowledge about the general rules that all human languages obey (Principles), and knowledge about the "permitted" ways that languages can vary from one another (Parameters). Empiricist approaches, do not assume any such inborn knowledge. Some empiricists like Jean Piaget, and those working in his tradition, see language development as the result of the child's striving to make sense of the world and to extract meaningful patterns, not just about language, but about all aspects of their environment. 
Language acquisition is seen as a product of general intellectual development rather than of a separate language processing capacity. In one respect, the Piagetian approach is similar to Chomsky's in that it focuses largely on factors internal to the child. However, other empiricist approaches tend to orient to factors external to the child and concentrate much more on the role of children's caregivers in helping them to "crack the code."

Chomsky's theory reflects a rationalist explanation of language acquisition: (a) the ultimate source of knowledge is the mind, not the external input. Grammar in the mind applies to, and to some degree determines, linguistic experience. (b) The essential mechanism of knowledge acquisition lies in the mind's ability to generate what is perceived as input, and to deduce new knowledge. (c) The Initial State is biologically programmed prior to experience in such a way that it makes linguistic experience possible and constrains its form.

\section{The language faculty}

Chomsky proposed and investigated a theory of the Initial State, i.e., the "Language Faculty" of the human species: "[T] here is a specific faculty of the mind/brain that is responsible for the use and acquisition of language, a faculty with distinctive characteristics that is apparently unique to the species in essentials." (Chomsky 1987). This Language Faculty "serves the two basic functions of rationalist theory: it provides a sensory system for the preliminary analysis of linguistic data, and a schematism that determines, quite narrowly, a certain class of grammars" (Chomsky 1975). The theory involves an innateness hypothesis (1986) which claims that "[I]t must be that the mind/brain provide a way to identify and extract the relevant information by means of mechanisms of some sort that are part of its biologically determined resources" (Chomsky 1988). Linguistic analysis and computation must be, at least in part, distinct from other forms of cognitive computation (reflecting a modular theory of mind).

\section{Chomsky's LAD}

Chomsky's early formulation of a Language Acquisition Device (LAD) logically explicated the preconditions for acquiring linguistic knowledge on the basis of projection from input (Chomsky 1984; Chomsky 1999). Formulation of the LAD appeared to beg the issue of language acquisition. It was often implied that a predetermined set of "specific language grammars" were innate (English, Swahili, Sinhala, Hindi, etc.) and that these merely needed to be "selected from," raising the question of how these grammars arise and how children judged whether the data were "compatible" with the grammar hypothesized (Peters 1972).

\section{From LAD to UG}

Chomsky moved the theory of the Language Faculty from LAD to Universal Grammar (UG). "[U]niversal grammar is part of the genotype specifying one aspect of the initial state of the human mind and brain." (Chomsky 1980). The definition of UG is formal, general and abstract, no longer suggesting access to a list of pre-defined grammars. UG differs from LAD in its formulation of what is proposed to be biologically programmed. "Universal grammar may be thought of as some system of principles, common to the species and available to each individual prior to experience" (Chomsky 1981). UG is bidimensional. "Universal Grammar might be defined as the study of the conditions that must be met by the grammars of all human languages" (Chomsky 1968) "In a highly idealized picture of language acquisition, UG is taken to be a characterization of children's pre-linguistic initial state" (Chomsky 1981) and of the "language faculty" (Chomsky 1981). If all natural languages follow a universal architecture, and the human species is so programmed, this would explain why universals of language exist and why any language is normally acquired in children's first years.

\section{The USAGE-BASED THEORY OF LANGUAGE ACQUISITION}

The usage-based approach to linguistic communication may be summarized in the two aphorisms: 1) meaning is use 2) structure emerges from use. 'Meaning is use' represents an approach to the functional or semantic dimension of linguistic communication. It originated with Wittgenstein (1953) and other pragmatically based philosophers of language, who wanted to combat the idea that meanings are things and instead focus on how people use linguistic conventions to achieve social ends. 'Structure emerges from use' represents an approach to the structural or grammatical dimension of linguistic communication. It is implicit in the work on grammaticalization and language change of many historical linguists, and has been made explicit by Langacker $(1987,2000)$ and other usage-based linguists, who want to combat the idea of a wholly formal grammar devoid of meaning and instead focus on how meaning-based grammatical constructions emerge from individual acts of language use. Drawing on the work of many other researchers, Tomasello (2003) proposes a usage-based theory of language acquisition. Paralleling the two aphorisms above, the proposal is that children come to the process of language acquisition, at around one year of age, equipped with two sets of cognitive skills, both evolved for other, more general functions before linguistic communication emerged in the human species: 1) intention-reading (functional dimension) 2) pattern-finding (grammatical dimension). 'Intention-reading' is what children must do to discern the goals or intentions of mature speakers when they use linguistic conventions to achieve social ends, and thereby to learn these conventions from them culturally. Intention-reading - including skills of joint attention - is the central cognitive construct in the so-called social-pragmatic approach to language acquisition (which is most often used in the study of word learning; Bruner 1983 Nelson 1996, Tomasello 1992, 2000, 2001). 'Pattern-finding' is what children must do to go productively beyond the individual utterances they hear people using around them to create abstract linguistic schemas or constructions. As a summary term for such things as categorization, analogy and distributional analysis, pattern-finding is the central 
cognitive construct in the so-called usage-based approach to the acquisition of grammar (Goldberg 1995, 2006, Tomasello 2000, 2003).

These theoretical positions on the functional and grammatical dimensions of language use and acquisition are minority positions in the field. Essentially, they represent the view that the pragmatics of human communication is primary, both phylogenetically and ontogenetically, and that the nature of conventional languages - and how they are acquired - can only be understood by starting from processes of communication more broadly.

\section{The CONNECTIONIST Modeling OF LANGUAGE ACQUiSition}

Connectionism has had an enormous impact in the theories that people have developed about many aspects of human cognition. Cognitive processes were assumed to be carried out by discrete operations that were executed in serial order. Memory was seen as distinct from the mechanisms that operated on it. And most importantly, processing was thought of in terms of symbolic rules of the sort that one finds in computer programming languages. These assumptions underlay almost all of the important cognitive theories up through the 1970s, and continue to be highly influential today. But as research within this framework progressed, the advances also revealed shortcomings. By the late 1970's, a number of people interested in human cognition began to take a closer look at some of basic assumptions of the current theories. In particular, some people began to worry that the differences between digital computers and human brains might be more important than hitherto recognized. In part, this change reflected a more detailed and accurate understanding about the way brains work. For example, it is now recognized that the frequency with which a neuron fires - an essentially analog variable - is more important than the single on/off (or digital) pulse from which spike trains are formed. But the dissatisfaction with the brain-as-computer metaphor was equally rooted in empirical failures of the digitally based models to account for complex human behavior.

This approach has stimulated a radical re-evaluation of many basic assumptions throughout cognitive science. One of the domains in which the impact has been particularly dramatic — and highly controversial — is in the study of language acquisition. Language is, after all, one of the quintessentially human characteristics. Figuring out just how it is that children learn language has to be one of the most challenging questions in cognitive science.

\section{CONCLUSION}

The study of language is notoriously contentious, but until recently, researchers who could agree on little else have all agreed on one thing: that linguistic knowledge is couched in the form of rules and principle (Pinker \& Prince, 1988). Current theories of language acquisition continue to reveal a tension between the philosophical paradigms of Rationalism and Empiricism. "Functionalist" and "usage based" models which have arisen in contrast to the leading Rationalist theory of Noam Chomsky reveal a central concern for understanding the interaction of children with the input data during the time course of language acquisition. This concern is also central to current studies of language acquisition in a linguistically based rationalist framework, although applications of these approaches differ critically in their proposals regarding the ultimate source and mechanisms of language acquisition. Both rationalist and empiricist approaches must now be tested against the empirical facts of language acquisition. Neither logical analyses nor computational modeling alone will be conclusive in building a comprehensive theory of language acquisition unless supplemented by empirical research.

\section{REFERENCES}

[1] Braine, M. (1971). The acquisition of language in infant and child. In C. Reed (ed.) The Learning of Language. New York: Appleton-Century-Crofts.

[2] Bruner, J. (1983). Child's Talk: Learning to Use Language. New York: Norton. (1986). Actual Minds, Possible Worlds. Cambridge, MA: Harvard University Press.

[3] Chomsky, N. (1959) “A review of B. F. Skinner's verbal behavior,” Language 35(1): 26-58.

[4] Chomsky, N. and M. Halle (1968). The Sound Pattern of English. New York: Harper and Row.

[5] Chomsky, N. (1975). Reflections on Language. New York: Pantheon Books.

[6] Chomsky, N. (1980). Rules and representations. Behavioral and Brain Sciences, 3, 1-61.

[7] Chomsky, N. (1981). Lectures on Government and Binding. Dordrecht: Foris.

[8] Chomsky, N. (1981). (1987). The Chomsky Reader. New York: Pantheon Books.

[9] Chomsky, N. (1984). Modular Approaches to the Study of the Mind. San Diego, CA: San Diego State University Press.

[10] Chomsky, N. (1988). Language and Problems of Knowledge: The Managua Lectures. Cambridge, MA: MIT Press.

[11] Chomsky, N. (1999). On the Nature, Use, and Acquisition of Language. In W. C. Ritchie and T. K. Bhatia (eds.), Handbook of Child Language Acquisition. San Diego, CA: Academic Press. 33-54.

[12] Cook, V. (1995) Multicompetence and effects of age. In D. Singleton and Z. Lengyel (eds) The Age Factor in Second Language Acquisition. Clevedon: Multilingual Matters.

[13] Goldberg, A. (1995). Constructions: A Construction Grammar Approach to Argument Structure. Chicago: University of Chicago Press.

[14] Goldberg, A. (2006). Constructions at Work: The Nature of Generalization in Language. Oxford: Oxford University Press.

[15] Kinsbourne, M. and Hiscock, M. (1977). Does cerebral dominance develop? In S. Segalowttz and F. Gruber (eds) Language Development and Neurological Theory. New York: Academic Press. 
[16] Krashen, S. (1973). Lateralization, language learning and the critical period: Some new evidence. Language Learning 23, 6374.

[17] Langacker, R. W. (1987). Foundations of Cognitive Grammar: Vol. 1. Stanford, CA: Stanford University Press.

[18] Langacker, R. W. (2000). A dynamic usage-based model. In M. Barlow \& S. Kemmer (Eds.), Usage-Based Models of Language (pp. 1-63). Stanford: CSLI.

[19] Lenneberg, E. (1967). Biological Foundations of Language. New York: Wiley.

[20] Long, M. (1990). Maturational constraints on language development. Studies in Second Language Acquisition 12, 251-85.

[21] McNeill, D. (1966). "Developmental psycholinguistics," in F.Smith and G.Miller (eds) The Genesis of Language, Cambridge, MA: MIT Press.

[22] Nelson, K. (1996). Language in Cognitive Development. New York: Cambridge University Press.

[23] Peters, A. (1977). "Language learning strategies: does the whole equal the sum of the parts?," Language 53:560-573.

[24] Pinker, S., \& Prince, A. (1988). Regular and irregular morphology and the psychological status of rules of grammar. BLS, 17, 230-251.

[25] Schachter, J. (1988). Second language acquisition and its relationship to Universal Grammar. Applied Linguistics 9, $219-35$.

[26] Tomasello, M. (1992). First Verbs: A Case Study of Early Grammatical Development. Cambridge: Cambridge University Press.

[27] Tomasello, M. (2000). Do young children have adult syntactic competence? Cognition, 74, 209-253.

[28] Tomasello, M. (2001). Perceiving intentions and learning words in the second year of life. In M. Bowerman \& S. Levinson (Eds.), Language Acquisition and Conceptual Development (pp. 132-158). Cambridge: Cambridge University Press.

[29] Tomasello, M. (2003). Constructing a Language: A Usage-Based Theory of Language Acquisition. Cambridge, MA: Harvard University Press.

[30] Wilson, R. (1999). Introduction: Philosophy. In. R. Wilson and F. Keil (eds.), MIT Encyclopedia of the Cognitive Sciences. Amherst: MIT Press. xv-xxxvii.

[31] Wittgenstein, L. (1953). Philosophical Investigations. New York: Macmillan.

Davood Mashhadi Heidar is currently a PhD candidate in Teaching English as a Foreign Language in Islamic Azad University, Khorasgan Branch. His areas of interest include First/Second language learning/acquisition, Discourse analysis, Critical discourse analysis, and ESP. 